\title{
KEBIJAKAN PERLAKUAN PIUTANG BERMASALAH PADA KOPERASI SIMPAN PINJAM ARTHA TUNGGAL MAKMUR
}

\author{
Eka Amelia Puri Prahesti \\ Fakultas Ekonomi Dan Bisnis \\ Universitas Muhammadiyah Jember \\ ekaamelia3110@gmail.com
}

\begin{abstract}
ABSTRAK
Tujuan dari penelitian ini yakni dapat mengetahui bagaimana kebijakan yang diterapkan Koperasi Simpan Pinjam Artha Tunggal Makmur dalam perlakuan piutang dan bagaimana standar penanganan yang dilakukan koperasi untuk menangani pinjaman bermasalah dan juga memberikan suatu hasil untuk mengajukan penghapusbukuan yang masih belum diterapkan. Ruang lingkup penelitian ni adalah profil dari Koperasi Simpan Pinjam Artha Tunggal Makmur dan kebijakan perlakuan piutang. Metode yang digunakan adalah wawancara langsung kepada manager,pembukuan dan pihak lapangan koperasi dan mengamati langsung dalam penanganan pinjaman bermasalah pada Koperasi Simpan Pinjam Artha Tunggal Makmur dan juga melakuan pengumpulan data dari berbagai sumber. Metode yang digunakan dalam penelitian ini adalah metode diskriptif kualitatif yakni suatu pembahasan yang dilakukan secara sistematis, berdasarkan fakta dan akurat salah objek yangn tengah diteliti. Penelitian ini membandingkan dalam sebelum dan sesudah diadakannya penghapusbukuan pinjaman bermasalah yang menjelaskan mengenai dampak yang berhubungan dengan koperasi. Hal ini ditujukan untuk mengajukan kebijakan penghapusbukuan kepada pihak pengurus koperasi untuk menerapkannya kebijakan tersebut agar tidak menambah buruk perputaran piutabg. Dan sebagai saran untuk Koperasi Simpan Pinjam Artha Tunggal Makmur agar menerapkan kebijakan penghapusbukan dan segera melakukan penanganan pinjaman bermasalah agar tidak ada lagi pinjaman pinjaman bermasalah yang dapat mmpengaruhi kinerja dan sisa hasil usaha koperasi.
\end{abstract}

Kata Kunci : penanganan pinjaman bermasalah, perputaran piutang

\section{ABSTRACT}

The purpose of this study is to find out how the policies implemented by the Savings and Loan Cooperative of Artha Tunggal Makmur in the treatment of accounts receivable and how the standard of handling carried out by cooperatives to deal with problem loans and also provide a result to submit write-offs that have not yet been implemented. The scope of this research is the profile of the Artha Tunggal Makmur Savings and Credit Cooperative and the policy on the treatment of accounts receivable. The methods used are direct interviews with managers, bookkeeping and cooperative field parties and observe directly in handling problem loans at the Savings and Loan Cooperative at Artha Tunggal Makmur and also collect data from various sources. The method used in this study is a qualitative descriptive method that is a discussion carried out systematically, based on facts and accurate wrong objects that are being studied. This study compares in before and after the holding of problematic loan write-offs that explained the impacts associated with cooperatives. This is intended to submit a writtenoff policy to the cooperative management to implement the policy so as not to add bad credit. And as a suggestion for the Savings and Loan Cooperative of Artha Tunggal Makmur to implement an abolition policy and immediately handle problem loans so that there are no more problem loans that can affect the performance and the remaining results of the cooperative effort.

Keywords: handling problem loans, receivable turnover 


\section{Pendahuluan}

Koperasi yang sangat populer di masyarakat yakni Koperasi Simpan Pinjam yaitu sebuah koperasi dimana usahanya untuk menghimpun dan memberikan dana kepada para masyarakat ( anggota). Sebagai instansi keuangan yang memberikan pinjaman, masalah yang sering dihadapi oleh koperasi simpan pinjam ialah kegagalan atau kemacetan pelunasan pinjaman (kredit bermasalah) yang dapat berpengaruh pada kesehatan koperasi. Kredit bermasalah (nonperforming Load) merupakan salah satu masalah utama dalan Koperasi Simpan Pinjam. Koperasi harus lebih hati hati dalam pemberian kredit dan lebih memperkuat manajemen kreditnya.

Upaya-upaya yang dapat ditempuh oleh koperasi dalam penanganan kredit bermasalah (Non Performing Loan/NPL) meliputi empat cara yaitu perubahan jadwal pinjaman ( reschedulling ), perubahan persyaratan (reconditioning), penataan kembali pinjaman kredit ( restructuring), dan penghapusbukuan

Nilai Piutang dan Cadangan Kerugian Piutang

\begin{tabular}{|c|c|c|c|}
\hline Akun & 31 Desember 2015 & $\begin{array}{c}\text { 31 Desember } \\
2016\end{array}$ & $\begin{array}{c}31 \text { Desember } \\
2017\end{array}$ \\
\hline Piutang & $\mathrm{Rp847.646.200}$ & $\mathrm{Rp} 1.613 .310 .750$ & $\mathrm{Rp} 1.428 .698 .119$ \\
\hline $\begin{array}{c}\text { Cadangan kerugian } \\
\text { piutang }\end{array}$ & $(\mathrm{Rp} \mathrm{59.187.500,-)}$ & $(\mathrm{Rp}$ 68.195.914,-) & $(\mathrm{Rp} 74.173 .428,-)$ \\
\hline
\end{tabular}

Perusahaan melakukan penaksiran cadangan kerugian piutang tak tertagih pada tiapakhir periode pembukuan. Cadangan tersebut merupakan nilai piutang yang berumur lebih dari 60 hari. Biaya cadangan kerugian piutang tersebut dicatat dalam laporan Sisa Hasil Usaha koperasi. Besar kecilnya biaya cadangan kerugian piutang tersebut menggambarkan naik turunnya biaya cadangan kerugian piutang setiap tahunnya. Jadi besar kecilnya kenaikan biaya cadangan kerugian juga mempengaruhi besar kecilnya Sisa Hasil Usaha (SHU). Oleh sebab itu, agar tidak membawa pengaruh negatif terhadap SHU maka koperasi harus mempunyai kebijakan yang tepat dalam menangani piutang bermasalah. Berdasarkan dari latar belakang yang telah disampaikan maka penulis melakukan sebuah penelitian dengan judul "Kebijakan perlakuan piutang bermasalah pada Koperasi Simpan Pinjam Artha Tunggal Makmur"

\section{TINJAUAN TEORI \\ Koperasi}

Koperasi berbeda dengan perusahaan yang komersil, perbedaannya yakni dari pemilik, dalam pemberuian keputusan/ peraturan koperasi dan karyawan. System kerakyatan dan system pelayanan yang diberikan yang gunanya untuk melayani anggota/masyarakat dan pemilik yang berperan penting terhadap menenaman modal yang didapatkan dari tranfsaksi yang terjadi kepada anggota dan adanya pembagian Sisa Hasil Usaha koperasi.

\section{Peranan koperasi beserta fungsinya}

Memperbaiki tingkat kehidupan ekonomi anggota merupakan salah satu fungsi dari koperasi . bertumbuhnya koperasi di Indonesia menunjukan bahwa 
masyarakat Indonesia telah memiliki sarana untuk memperjuangkan ekonomi mereka. Dengan berdasarkan prinsip keluargaan dan rasa bergotong royong untuk membentuk dan memperbaiki perekonomian masyarakat merupakan perasan koperasi.

\section{Macam dari Jenis Koperasi}

1. Koperasi Konsumsi

2. Koperasi Produksi

3. Koperasi Simpan Pinjam (KSP)

4. Koperasi Jasa

5. Koperasi Serba Usaha/Koperasi Unit Desa (KUD)

\section{Tolak Ukur Keberhasilan Koperasi}

Pada tahun 1997/1998 tolak ukuran keberhasilan koperasi yang telah dinyatakan oleh Dinas Koperasi dan Direktorat pembinaan pengusaha kecil :

1. Anggota Minimal $25 \%$

2. Memiliki Modal minimal sebesar Rp. 25.000.000,00.

3. Laporan layak tanpa cacat.

\section{Kesehatan koperasi simpan pinjam dengan Kualitas Aktiva Produktif}

Kualitas dari aktiva yang produktif ini dapat diukur dari 4 rasio. 4 rasio tersebut ialah rasio pinjaman untuk anggota terhadap jumlah pinjaman diberikan, rasio pinjaman kredit yang bermasalah terhadap pinjaman kredit yang diberikan, rasio cadangan pinjaman risiko terhadap pinjaman kredit bermasalah dan rasio pinjaman beresiko terhadap pinjaman kredit yang telah diberikan.

1. Rasio pinjaman untuk anggota terhadap jumlah pinjaman diberikan.

2. Rasio terhadap pinjaman yang bermasalah

3. Rasio cadangan resiko terhadap pinjaman yang bermasalah

4. Rasio pinjaman yang berisiko terhadap total pinjaman yang diberikan kepada anggota

\section{Piutang}

Piutang (receivable) adalah suatu jenis transaksi yang mengklaim jasa uqng atau barang dan piutang merupakan suatu transaksi antara produsen dan konsumen. Tertagihanya selama kurang lebi satu tahun atau selama satu siklus aperasi usaha yang sedanng berjalan merupakan harapan dari piutang lancardan piutang yang lain adalah kelompok pitang tidak lancar atau piutang jangka panjang.

\section{Penggolongan Piutang Dalam Koperasi}

Koperasi terdapat begitu banyak jenis piutang yang dimiliki. Piutang dalam koperasi terdapat 3 klasifikasi berdasarkan jenis dan asalnya yaitu:

1. Piutang Anggota Koperasi

2. Piutang Bukan Anggota Koperasi

3. Piutang Karyawan

Tagihan koperasi terhadap karyawan koperasi yang biasanya pembayara piutang karyawan dilakukan dengan pemotongan gaji pada bulan berikutnya. 


\section{Pengakuan Piutang}

Pengakuan piutang simpan pinjam dalam koperasi terjadi jika koperasi memberikan pinjaman kepada anggota koperasi sehingga koperasi memiliki hak klaim kepada anggota tersebut. Pengakuan piutang simpan pinjam menurut Rudianto (2010: 126) adalah piutang simpan pinjam diakui sebesar jumlah bruto (nilai jatuh tempo).

\section{Penilaian dan Pelaporan Piutang}

Piutang telah dinilai sebesar nilai bersihnya (dikurangi dengan cadangan kerugian piutang) namun kedua jumlah tersebut harus disajikan sebesar nilai transaksi yang sebenarnya dalam neraca dan cadangan kerugian piutang disajikan sebagai pengurang dari saldo piutang usaha untuk memperoleh netto piutang yang akan terealisasi.

\section{Penanganan Piutang}

Untuk mencapai hasil yang optimal, maka perusahaan memerlukan informasi dan analisa kredit yang tepat. Menurut calon pelanggan menurut Riyanto (2001 : 78) penganalisaan disebut dengan istilah "The Five C's of Credit" yakni:

1. Character (kepribadian)

2. Capacity (kemampuan)

3. Capital (modal)

4. Colateral (jaminan)

5. Conditions (kondisi)

\section{Metode Penghapusan Piutang}

Penjualan yang berdasar selain penjualan tunai beresiko dalam menimbulkan kegagalan untuk penagihan piutang. Pencatatan piutang usaha tidak dapat tertagih menurut Skousen (2009:417), dibagi menjadi dua yakni:

1. Metode Penghapusan Langsung

2. Metode Penyisihan

\section{Penyelamatan Yang Dilakukan Untuk Mengatasi Kredit Macet}

Tidak semua pinjaman atau piutang usaha dalam lembaga keuangan semua berjalan lancar. Terdapat pula pinjaman bermasalah (macet). terdapat beberapa cara, diantaranya adalah:

1. Rescheduling ( Penjadwalan kembali )

2. Reconditioning

3. Restructuring

4. Penyitaan jaminan

5. Penghapusan kredit

Penghapusan kredit merupakan tindakan sudah lazim dilakukan dikalangan perbankan untuk menurunkan rasio kredit bermasalah agar tingkat kesehatan koperasi tetap terjaga dengan baik. Penghapusan kredit ditujukan untuk mengeluarkan rekening aset yang tidak produktif, seperti kredit macet yang tidak dapat ditagih, penghapusan kredit bukan berarti sebatas menghapus kewajiban 
debitur namun pihak bank tetap memiliki hak dalam melakukan penagihan atas kredit macet itu sebisa mungkin, dengan harapan debitur bersedia melunasi semua kewajiban yang dibebankan.

\section{Perputaran Piutang}

1. Rasio Receivable Turn Over

Rumus: $R T O=\frac{\text { Penjualan Kredit }}{\text { Piutang rata-rata }}$

Dimana:

Piutang Rata - rata $=\frac{\text { Piutang periode sebelumnya }+ \text { piutang selama satu periode }}{2}$

2. Rasio Average Collaction Period

Rumus: $A C P=\frac{360}{\text { Receivable turn over }}$

3. Rasio Tunggakan

Rumus: Rasio Tunggakan $=\frac{\text { Total piutang tak tertagih }}{\text { Penjualan kredit }} \times 100 \%$

4. Rasio Penagihan

Rumus: Rasio Penagihan $=\frac{\text { Total piutang tertagih }}{\text { Total piutang periode }} \times 100 \%$

Tinjauan Penelitian Terdahulu

\begin{tabular}{|c|c|c|c|}
\hline $\mathrm{NO}$ & $\begin{array}{c}\text { NAMA } \\
\text { PENELITIAN }\end{array}$ & JUDUL PENELITIAN & HASIL PENELITIAN \\
\hline 1 & $\begin{array}{l}\text { Susilawati, R. } \\
\text { A. E., \& } \\
\text { Purwanto, N. } \\
(2016)\end{array}$ & $\begin{array}{l}\text { Analisis } \\
\text { Rescheduling \& } \\
\text { Reconditioning } \\
\text { Piutang Mitra } \\
\text { Binaan Untuk } \\
\text { Meningkatkan } \\
\text { Kinerja Keuangan } \\
\text { Pkbl Di Perum Jasa } \\
\text { Tirta I }\end{array}$ & $\begin{array}{l}\text { Hasil penelitian ini } \\
\text { menunjukkan bahwa } \\
\text { penggunaan metode } \\
\text { rescheduling dan } \\
\text { reconditioning untuk } \\
\text { pemulihan pinjaman } \\
\text { merupakan langkah yang } \\
\text { tepat guna meminimalisasi } \\
\text { resiko tidak terbayarnya } \\
\text { piutang atau resiko } \\
\text { penggolongan kualitas } \\
\text { piutang dipiutang bermasalah } \\
\text { yang berdampak pada kinerja } \\
\& \text { prestasi unit pkbl di Perum } \\
\text { Jasa Tirta I. }\end{array}$ \\
\hline 2 & $\begin{array}{l}\text { Soedarsa, H. } \\
\text { G., \& Natalia, } \\
\text { D. (2016). }\end{array}$ & $\begin{array}{l}\text { Analisis Tingkat } \\
\text { Kesehatan Koperasi } \\
\text { Simpan Pinjam } \\
\text { Mukti Bina Usaha } \\
\text { Kelurahan } \\
\text { Muktisari } \\
\text { Kota Banjar Jawa } \\
\text { Barat } \\
\text { Tahun 2011-2013 }\end{array}$ & $\begin{array}{l}\text { Aspek kualitas } \\
\text { aktiva produktif secara rerata } \\
\text { mendapat skor } 13,92 \text { dan } \\
\text { berada dalam kategori } \\
\text { kurang sehat; }\end{array}$ \\
\hline
\end{tabular}




\begin{tabular}{|l|l|l|l|}
\hline 3 & $\begin{array}{l}\text { Suarjaya, I. N., } \\
\text { Cipta, W., \& } \\
\text { Zukhri, A. } \\
\text { (2015). }\end{array}$ & $\begin{array}{l}\text { Analisis Penyelesaian } \\
\text { Kredit Macet Pada } \\
\text { Koperasi Pasar Srinadi } \\
\text { Klungkung }\end{array}$ & $\begin{array}{l}\text { Upaya yang dilakukan untuk } \\
\text { mengatasi kredit macet pada } \\
\text { Koperasi Pasar Srinadi } \\
\text { Klungkung Yaitu } \\
\text { Rescheduling (penjadwalan } \\
\text { kembali), restructuring } \\
\text { (persyaratan kembali), } \\
\text { penyitaan jaminan, dan } \\
\text { penghapusan kredit }\end{array}$ \\
\hline 4 & $\begin{array}{l}\text { Tri Wahyuni, } \\
\text { D. (2011). }\end{array}$ & $\begin{array}{l}\text { Standar Penanganan } \\
\text { Pinjaman Bermasalah } \\
\text { Pada Koperasi Simpan } \\
\text { Pinjam Sarana Aneka } \\
\text { Jasa }\end{array}$ & $\begin{array}{l}\text { KSParana Aneka Jasa telah } \\
\text { melakukan segala prosedur } \\
\text { standar penanganan pinjaman } \\
\text { kredit bermasalah secara } \\
\text { tepat sehingga debitur tidak } \\
\text { merasa dirugian dan telah } \\
\text { tercapai kesepakatan antara 2 } \\
\text { belah pihak. }\end{array}$ \\
\hline
\end{tabular}

Penelitian yang akan dilakukan penulis dengan menggunakan penelitian terdahulu adalah mengetahui peranan besar pengakuan cadangan kerugian piutang terhadap besarnya outstanding pinjaman yang ada dalam koperasi dalam penanganannya, pencatatan dan pengelolaan lanjutan keputusan tentang proses piutang yang benar benar tidak tertagih. Dalam koperasi simpan pinjam Artha Tunggal Makmur walau sudah dilakukan pencadangan dalam piutang anggota, tetap ada biaya pencadangan sebagai selisih dari kenaikan atau penurunan jumlah cadangan kerugian dengan bulan sebelumnya. Dengan dimasukkannya dalam biaya maka sangat berpengaruh pada laporan laba rugi koperasi setiap bulannya dan menentukan besar kecilnya sisa hasil usaha koperasi.

\section{METODOLOGI PENELITIAN}

\section{Desain Penelitian}

Penelitian ini penulis menggunakan metode yakni metode penelitian deskriptif kualitatif. Peneliti ingin menganalisis bagaimana pencatatan dan penanganan piutang bermasalah agar bisa mengurangi cadangan kerugian piutang.

\section{Jenis dan Sumber Data}

Teknik Pengumpulan teknik wawancara dan dokumentasi. Teknik wawancara dalam penelitian ini menggunakan teknik wawancara secara umum, yaitu $5 \mathrm{~W}$ dan $1 \mathrm{H}$ (What, Who, Where, When, Why).

\section{Teknik Pengumpulan Data}

1. Wawancara

2. Dokumentasi .

3. Triangulasi

4. Uji Keabsahan Data 


\section{Teknik Analisis Data}

Teknik analisis deskriptif yang digunakan untuk menganalisa data yaitu dengan cara:

1. Mengumpulkan data Piutang dari bagian pembukuan tahun 2015 s/d 2017

2. Menganalisa kebijakan perlakuan perlakuan piutang bermasalah yang dilakukan Koperasi Simpan Pinjam Artha Tunggal Makmur.

3. Menganalisa dampak yang ditimbulkan dari pinjaman bermasalah dan stategi pemulihan yang dilakukan Koperasi Simpan Pinjam Artha Tunggal Makmur.

4. Menganalisa dampak yang ditimbulkan setelah kebijakan penghapusan piutang bermasalah terlah diterapkan pada Koperasi Simpan Pinjam Artha Tunggal Makmur.

5. Membandingkan hasil sebelum dan sesudah diterapkannya penghapusbukuan pinjaman bermasalah pada Koperasi Simpan Pinjam Artha Tunggal Makmur.

6. Memberikan kesimpulan dan saran dari hasil evaluasi tersebut.

\section{HASIL DAN PEMBAHASAN \\ Hasil Penelitian \\ Gambaran Umum Koperasi Simpan Pinjam Artha Tunggal Makmur Sejarah Singkat}

Koperasi Simpan Pinjam Artha Tunggal Makmur yang berkantor pusat di Kecamatan Genteng - Banyuwangi yang berdiri sejak 19 Januari 2005. Seiring perkembangan koperasi Simpan Pinjam Artha Tunggal Makmur membuka kantor cabang di beberapa kecamatan lain di Banyuwangi. Hingga saat ini KSP Artha Tunggal Makmur telah memiliki 6 unit cabang yang tersebar di wilayah Banyuwangi, salah satunya beralamat di Jl.Raya Kalibaru (selatan Indomaret) yang didirikan pada tanggal 3 Agustus 2009 dan menjadi obyek dalam penelitian ini. Koperasi Simpan Pinjam Artha Tunggal Makmur Banyuwangi, telah berbadan hukum: No. 518/09/BH/VI/429.106/2005.

\section{Pembahasan}

Analisis Data

Data Penelitian Kredit Macet dan NPL (Non Performing Loan). Berikut adalah data Kredit Macet dan NPL pada Koperasi Simpan Pinjam Artha Tunggal Makmur periode 2015 - 2017:

\begin{tabular}{|c|c|c|c|}
\hline Tahun & $\begin{array}{c}\text { Kredit Bermasalah } \geq 120 \\
\text { hari }\end{array}$ & $\begin{array}{c}\text { Kredit diragukan } 60 \text { hari s/d } \\
120 \text { hari }\end{array}$ & Total kredit macet \\
\hline 2015 & Rp. $35.512 .500,00$ & Rp. $23.675 .000,00$ & Rp. $59.187 .500,00$ \\
\hline 2016 & Rp. $46.373 .221,00$ & Rp. $21.822 .693,00$ & Rp. $68.195 .914,00$ \\
\hline 2017 & Rp. 55.765.023,00 & Rp. $18.408,405,00$ & Rp. $74.173 .428,00$ \\
\hline
\end{tabular}

\begin{tabular}{|c|c|c|c|c|c|}
\hline Tahun & Total Kredit & $\begin{array}{c}\text { Kredit } \\
\text { Bermasalah } \geq 120 \\
\text { hari }\end{array}$ & $\begin{array}{c}\text { Kredit diragukan 60 } \\
\text { hari s/d 120 hari }\end{array}$ & $\begin{array}{c}\text { Kredit Kurang Lancar } \\
\text { 1 hari s/d 59 hari }\end{array}$ & Kredit Lancar \\
\hline 2015 & Rp 847.646.200,00 & Rp. 35.512.500,00 & Rp. 23.675.000,00 & Rp. 141.922.566,00 & Rp. 646.536.134,00 \\
\hline 2016 & Rp1.613.310.750,00 & Rp. 46.373.221,00 & Rp. 21.822.693,00 & Rp. 386.278.709,00 & Rp.1.158.836.127,00 \\
\hline 2017 & Rp1.428.698.119,00 & Rp. 72.733.471,00 & Rp. 1.439.957,00 & Rp. 270.904.939,00 & Rp 1.083.619.752,00 \\
\hline
\end{tabular}




\begin{tabular}{|l|l|l|c|c|}
\hline Tahun & \multicolumn{1}{|c|}{ Total Pinjaman Kredit } & $\begin{array}{c}\text { Total Piutang } \\
\text { Pinjaman Tertagih }\end{array}$ & $\begin{array}{c}\text { Total Piutang Tak } \\
\text { Tertagih 1 hari }-59 \\
\text { hari }\end{array}$ & $\begin{array}{c}\text { Total Piutang Tak } \\
\text { Tertagih } \geq 60 \text { hari }\end{array}$ \\
\hline 2015 & Rp847.646.200,00 & Rp. 646.536.134,00 & Rp. $141.922 .566,00$ & Rp. 59.187.500,00 \\
\hline 2016 & Rp1.613.310.750,00 & Rp. $1.158 .836 .127,00$ & Rp. 386.278.709,00 & Rp. 68.195.914,00 \\
\hline 2017 & Rp1.428.698.119,00 & Rp. $1.083 .619 .752,00$ & Rp. 270.904.939,00 & Rp. 74.173.428,00 \\
\hline
\end{tabular}

\begin{tabular}{|c|c|c|c|}
\hline Tahun & Total Pinjaman Kredit & $\begin{array}{c}\text { Total Piutang Pinjaman } \\
\text { Tertagih }\end{array}$ & Total Piutang Tak Tertagih \\
\hline 2015 & Rp847.646.200,00 & Rp. $646.536 .134,00$ & Rp. 201,110,066,00 \\
\hline 2016 & Rp1.613.310.750,00 & Rp. $1.158 .836 .127,00$ & Rp. 454,474,623,00 \\
\hline 2017 & Rp1.428.698.119,00 & Rp. $1.083 .619 .752,00$ & Rp. 345.078.367,00 \\
\hline
\end{tabular}

Sumber: data diolah dari Laporan Pinjaman Koperasi Simpan Pinjam

Artha Tunggal Makmum

Untuk piutang tak tertagih dalam kelompok umur 31 - 60 hari,Koperasi Simpan Pinjam Artha Tunggal Makmur mengkategorikan piutang pada kelompok umur tersebut dalam kategori kurang aman, yaitu berarti piutang tak tertagih pada perusahaan hanya $70 \%$ yang dapat ditagih. Sedangkan untuk piutang tak tertagih dalam kelompok umur 61 - 120 hari Koperasi Simpan Pinjam Artha Tunggal Makmur mengkataegorikan piutang pada kelompok umur tersebut pada kategori piutang tidak aman (macet ) berarti piutang tersebut hanya 20\% saja yang dapat ditagih. Pinjaman yang telah terlambat $>120$ hari juga dikategorikan macet (blacklist) dikarenakan sudah $100 \%$ tidak dapat ditagih kembali.

\section{Kebijakan Perlakuan Perlakuan Piutang Bermasalah Yang Dilakukan Koperasi Simpan Pinjam Artha Tunggal Makmur}

Dalam laporan pembukuan Koperasi Simpan Pinjam Artha Tunggal Makmur, pinjaman yang bermasalah dalam koperasi dicatat dalam bentuk metode cadangan kerugian. Setiap tahunnya cadangan kerugian piutang terus menambah. Pinjaman bermasalah adalah pinjaman yang mengalami keterlambatan pembayaran lebih dari 60 hari. Selanjutnya dalam laporan pinjaman bermasalah, pinjaman dikategorikan dalam terlambat kurang dari 2 tahun dan terlambat lebih dari 2 tahun. Pinjaman yang sudah melewati 2 tahun dikategorikan sebagai pinjaman yang tidak bisa ditagih lagi. Meskiipun terdapat pinjaman yang sudah terlambat melebihi 2 tahun akan tetapi dalam Koperasi Simpan Pinjam Artha Tunggal Makmur belum di adakannya kebijakan penghapus bukuan piutang. Hal ini mempengaruhi laba perusahaan (SHU) dan kesehatan Koperasi Simpan Pinjam Artha Tunggal Makmur.

Dampak Yang Ditimbulkan Dari Pinjaman Bermasalah Dan Stategi Pemulihan Pinjaman Bermasalah Yang Dilakukan Koperasi Simpan Pinjam Artha Tunggal Makmur

\section{Dampak Yang Ditimbulkan Dari Pinjaman Bermasalah}

Tingkat Perputaran Piutang

a) Rasio Receivable Turn Over (RTO)

Rumus: RTO = Pinjaman Kredit

Dimana:

Piutang Rata-rata

Piutang rata-rata $=\underline{\text { Piutang periode sebelumnya }+ \text { piutang selama } 1 \text { periode }}$

2 
Berikut ini adalah perhitungan RTO:

(1) Tahun 2016

$$
\begin{aligned}
& \mathrm{RTO}=\frac{1.613 .310 .750}{327.792 .345} \\
& =655.584 .689 \\
& 2 \\
& =327.792 .345
\end{aligned}
$$

(2) Tahun 2017

$$
\begin{aligned}
& \text { RTO }=\frac{1.428 .698 .119}{399.776 .495} \\
& \text { RTO }=3,57 \text { kali }
\end{aligned}
$$

Dimana: Piutang rata-rata $=454.474 .623+345.078 .367$

$$
=\frac{799.552 .990}{2}
$$

Piutang rata-rata $=399.776 .495$

b) Rasio Average Collaction Period (ACP)

Rumus: $\mathrm{ACP}=\frac{360}{\mathrm{RTO}}$

(1) Tahun 2016

$$
\begin{aligned}
\mathrm{ACP} & =\frac{360}{4,92 \text { kali }} \\
& =73 \text { hari }
\end{aligned}
$$

(2) Tahun 2017

$$
\begin{aligned}
& \mathrm{ACP}=\frac{360}{3,57 \mathrm{kali}} \\
& \mathrm{ACP}=101 \text { hari }
\end{aligned}
$$

c) Rasio Tunggakan

Rumus: Rasio Tunggakan $=\frac{\text { Total pinjaman bermasalah }}{\text { Total Pinjaman Kredit }} \times 100 \%$

Berikut ini adalah perhitungana rasio tunggakan:

- Tahun 2016

$$
\begin{aligned}
\text { Rasio Tunggakan } & =\frac{68.195 .914}{1.613 .310 .750} \times 100 \% \\
\text { Rasio Tunggakan } & =4 \%
\end{aligned}
$$

- $\quad$ Tahun 2017

$$
\begin{aligned}
& \text { Rasio Tunggakan }=\frac{74.173 .428}{1.428 .698 .119} \times 100 \% \\
& \text { Rasio Tunggakan }=5 \%
\end{aligned}
$$

d) Rasio Penagihan

Rumus: Rasio Penagihan $=$ Total Piutang Tertagih $\quad \times 100 \%$

Berikut ini adalah perhitungana rasio penagihan: 
(1) Tahun 2016

Rasio Penagihan $=\underline{1.158 .836 .127} \times 100 \%$

1.613 .310 .750

Rasio Penagihan $=72 \%$

(2) Tahun 2017

Rasio Penagihan $=\frac{1.083 .619 .752}{1.428 .698 .119} \times 100 \%$

Rasio Penagihan $=76 \%$

$$
1.428 .698 .119
$$

Hasil perhitungan rasio - rasio tersebut dapat dilihat dari table ini :

\begin{tabular}{ccccc}
\hline Tahun & RTO & ACP & $\begin{array}{c}\text { Rasio } \\
\text { Tunggakan }\end{array}$ & $\begin{array}{c}\text { Rasio } \\
\text { Penagihan }\end{array}$ \\
\hline $\mathbf{2 0 1 6}$ & $4,92 \mathrm{kali}$ & $73 \mathrm{Hari}$ & $4 \%$ & $72 \%$ \\
$\mathbf{2 0 1 7}$ & $3,57 \mathrm{kali}$ & 101 Hari & $5 \%$ & $76 \%$ \\
\hline
\end{tabular}

\section{Stategi Pemulihan Pinjaman Bermasalah Yang Dilakukan Koperasi Simpan Pinjam Artha Tunggal Makmur}

Setelah melakukan penagihan,pemberitahuan via telepon,sms dan pemberian SP I,II,III beberapa langkah yang telah dilakukan koperasi simpan pinjam artha tunggal makmur diantaranya adalah:

1. (resceduling) atau perubahan jadwal pinjaman

2. Penyelamatan kredit dengan Reconditioning dan Restrukturing

3. Penyelamatan kredit dengan Reorganisasi dan rekapitulasi.

a. Lelang jaminan

b. Proses penghapus bukuan

\section{Dampak Yang Ditimbulkan Setelah Kebijakan Penghapusan Pinjaman Bermasalah Telah Diterapkan Pada Koperasi Simpan Pinjam Artha Tunggal Makmur}

Setelah mengetahui dampak yang ditimbulkan oleh pinjaman bermasalah apabila tidak dilakukannya atau diterapkannya kebijakan penghapusan piutang pada Koperasi Simpan Pinjam Artha Tunggal Makmur maka akan mengalami dampak yang telah disebutkan tadi. Pihak pengurus akan mempertimbangkan hal terssebut dan meminta kantor untuk memberikan laporan yang terkait. Setiap kantor cabang nantinya akan diminta untuk memberikan beberapa laporan yaitu laporan pinjaman bermasalah, neraca ,laporan sisa hasil usaha dan laporah khusus. Laporan khusus yaitu laporan pinjaman bermasalah yang dilengkapi dengan data - data kelengkapan dan laporan hasil dari penagihan terakhir pada nasabah kepada audit internal koperasi. Setelah diberikannya laporan tersebut maka pihak audit melakukan seleksi mana pinjaman yang bisa dihapus dan mana yang tidak. Kebijakan penghapusan pinjaman bermasalah pada Koperasi Simpan Pinjam Artha Tunggal Makmur tersebut masih dilakukan dalam proses hingga saat ini.

Pemilihan penghapusan pinjaman bermasalah berdasarkan pada:

1. Lama keterlambatan. Keterlambatan harus melebihi 2 tahun dari terakhir pembayaran angsuran.

2. Keterangan keterlabatan dari laporan hasil penagihan terakhir

3. Penanganan yang sudah dilakukan sebelum mengajukan kebijakan untuk penghapusan piutang. 
Untuk dapat melihat bagaimana kondisi piutang koperasi apabila telah selesai melakukan penghapusan piutang, dapat melakukan perhitungan Berikut ini adalah perhitungannya :

a) Rasio Receivable Turn Over (RTO)

Rumus : $\mathrm{RTO}=$ Pinjaman Kredit

$$
\text { Pinjaman Rata-rata }
$$

$\mathrm{RTO}=\ldots \ldots \ldots \ldots . . \mathrm{kali}$

Dimana:

Pinjaman rata-rata $=\underline{\text { Pinjaman periode sebelumnya }+ \text { pinjaman selama } 1 \text { periode }}$

Berikut ini adalah perhitungan RTO:

- Tahun 2017

$$
\mathrm{RTO}=\frac{1.370 .385 .187}{370.620 .029}
$$

$\mathrm{RTO}=3,69$ kali

Dimana: Piutang rata-rata $=\underline{454,474,623+286.765 .435}$

$$
=\frac{741.240 .058}{2}
$$

Piutang rata-rata $=370.620 .029$

b) Rasio Average Collaction Period (ACP)

$$
\begin{aligned}
& \text { Rumus: ACP }=\frac{360}{\text { RTO }} \\
& \text { Tahun } 2017 \\
& \text { ACP }=\frac{360}{3,69 \text { kali }} \\
& \text { ACP }=97 \text { hari }
\end{aligned}
$$$$
\text { RTO }
$$

c) Rasio Tunggakan

Rumus: Rasio Tunggakan $=$ Total pinjaman bermasalah $\quad x 100 \%$

$$
\text { Total Pinjaman Kredit }
$$

Berikut ini perhitungan dari rasio tunggakan:

- Tahun 2017

$$
\text { Rasio Tunggakan }=\frac{15.860 .476}{1.370 .385 .187} \times 100 \%
$$

Rasio Tunggakan $=1 \%$

d) Rasio Penagihan

Rumus: Rasio Penagihan $=$ Total Piutang Tertagih $\mathrm{x} 100 \%$ Total Piutang Periode

Berikut ini hasil perhitungan rasio penagihan:

- Tahun 2017

$$
\begin{aligned}
& \text { Rasio Penagihan }=\frac{1.083 .619 .752}{1.370 .385 .187} \times 100 \% \\
& \text { Rasio Penagihan }=79 \%
\end{aligned}
$$

Hasil perhitungan rasio - rasio tersebut dapat dilihat dari table ini :

Perhitungan rasio setelah penghapusan 


\begin{tabular}{|c|c|c|c|c|}
\hline Tahun & RTO & ACP & $\begin{array}{c}\text { Rasio } \\
\text { Tunggakan }\end{array}$ & $\begin{array}{c}\text { Rasio } \\
\text { Penagihan }\end{array}$ \\
\hline 2017 & $3,69 \mathrm{kali}$ & $97 \mathrm{Hari}$ & $1 \%$ & $79 \%$ \\
\hline
\end{tabular}

Setelah mengetahui dampak dampak yang ditimbukan apabila pinjaman bermasalah pada koperasi simpan pinjam artha tunggal makmur, pihak pengurus dapat mempertimbangkan kebijakan penghapusan piutang. Apabila diterapkannya maka bentuk laporan tersendiri khusus untuk pinjaman bermasalah yang dihapuskan. Laporan tersebut bersikan data pokok pinjaman, total bunga pinjaman, total biaya keterlambatan, data anggunan nasabah. Untuk BPKB pinjaman bermasalah yang telah dihapuskan ditempatkan pada tempat yang terpisah.

Membandingkan Hasil Sebelum Dan Sesudah Diterapkannya Penghapusan Piutang Bermasalah Pada Koperasi Simpan Pinjam Artha Tunggal Makmur Perubahan yang ada yakni ;

- Perubahan rasio Receivable Turn Over ( RTO ), perubahan perputaran piutang yang sebelum dihapus adalah 3,57 kali maka setelah dihapuskan menjadi 3,69 kali. Hasil itu tidak mencapai atau tidak bisa menyamai di tahun 2016 dikarenakan jumlah pemberian kredit di tahun 2017 yang nominalnya menurun dari tahun 2016.

- Perubahan Rasio Average Collaction Period (ACP) pengembalian atau keluar masuknya kas berubah lebih cepat dari sebelum dibapuskannya. Sebelum di hapuskan penerimaan kas untuk pengembalian pinjaman adalah 101 hari, akan tetapi apabila sudah diterapkannya penghapusan piutang perputarannya adalah 97 hari. Memang hal tersebut untuk penerimaan kas dalam pengembalian pinjaman akan tetapi pihak nasabah melakukan pembayaran bunga dalam setiap bulannya . hal ini dapat pusa menjadikan pendapatan dalam koperasi walaupun belum ada pengembalian pinjaman / pokok pinjaman nasabah tetap membayarkan bunga dari pinjaman.

- Perubahan rasio tunggakan pinjaman atau NPL pinjaman menjadi lebuh baik. Awalnya 4\% sebelum pinjaman bermasalah di hapuskan menjadi $1 \%$ setelah dihapuskan. Dalam hal ini bisa digunakan untuk kriteria kesehatan koperasi.

- Perubahan penilaian rasio penagihan pinjaman menjadi lebih baik.

\section{KESIMPULAN DAN SARAN KESIMPULAN}

Setelah melakukan analisis dan pemberian hasil analisis maka penulis telah melakukan penelitian sebagai skripsi yang berjudul Kebijakan Perlakuan Piutang Bermasalah Pada Koperasi Simpan Pinjam Artha Tunggal Makmur dapat mengambil kesimpulan seperti :

1. Kebijakan perlakuan pinjaman pada Koperasi Simpan Pinjam Artha Tunggal Makmur yang diterapkan sejak awal berdiri yaitu menggunakan metode penyisihan piutang. Perlakuan tersebut untuk mencadangkan jumlah piutang yang tidak dapat tertagih pada periode tersebut. Pencatatan cadabgan kerugian tersebut diambil dari jumlah nominal pinjaman yang tidak dapat tertagih dengan keterlambatan $\geq 60$ hari. Pinjaman yang telah memiliki keterlambatan dan masuk sebagai pencadangan pinjaman dikategorikan sebagai pinjaman 
macet. Beberapa kendala yang dapat membuat pinjaman tersebut mengalami keterlambatan yakni faktor internal dan eksternal

2. Setelah melakukan penelitian dan perbandingan maka dapat disimpulan akibat yang mucul apabila penghapusbukuan telah diterapkan pada koperasi simpan pinjam artha tunggal makmur yaitu dapat mempercepat perputaran piutang koperasi,mempercepat perputaran keluar masuknya kas koperasi dan membuat NPL menjadi lebih baik

\section{SARAN}

1. KSP Artha Tunggal Makmur dapat melakukan beberapa penyelamatan kredit atau dalam penanganan pinjaman bermasalah dpat melakukan beberapa langkah :

a. Penyelamatan dari penyebab internal koperasi

i. Melakukan kosultasi pada karyawan dan pemberian pengarahan dan otivasi supaya karyawan koperasi simpan pinjam artha tunggal makmur dapat meningkatkan kinerja mereka .

ii. Sering melakukan rapat dalam kantor untuk melakukan bertukar informasi.

iii.Lebih berhati-hati dalam melakuakm survey yang baik dan benar untuk mengurangi resiko adanya pinjaman bermasalah dikemudian hari.

b. Faktor eksternal

Dari pihak Koperasi Simpan Pinjam Artha Tunggal Makmur melakukan kooerdinasi serta pengarahan kepada peminjam yaitu anggota agar usaha anggota dapat berjalan lancar dan tidak menghambat dalam pembayaran pinjaman yang berdampak negatif pula pada Koperasi Simpan Pinjam Artha Tunggal Makmur.

2. Koperasi Simpan Pinjam Artha Tunggal Makmur sebaiknya mengambil langkah penghapusan piutang yang benar-benar dihapus setelah dilakukan mengolahan datanya. Apabila nantinya sudah dilakukan penghapusan piutang, pinjaman yang telah dihapuskan tersebut agar dibuatkan laporan tersendiri karena apabila salah satu peminjam akan menyelesaikan pinjamannya bisa dilihat dari laporan tersendiri yang terpisah dari laporan keuangan bulanan. Dengan adanya penghapusan piutang penilaian kesehatan Koperasi Simpan Pinjam Artha Tunggal Makmur menjadi sehat. Setelah diadakannya penghapusan piutang maka kantor cabang bisa membenahi tatanan managemen yang sebisa mungkin tidak menambah cadangan kerugian piutang.

\section{DAFTAR PUSTAKA}

Tri Wahyuni, D. (2011). Standar Penanganan Pinjaman Bermasalah Pada Koperasi Simpan Pinjam Sarana Aneka JASA (Doctoral dissertation, Universitas Sebelas Maret).

Dirdjosisworo, S. (1997). Hukum Perusahaan Mengenai Bentuk-Bentuk Perusahaan (Badan Usaha) Di Indonesia. Mandar Maju.

Indonesia, R. (1992). Undang-Undang No. 25 Tahun 1992 Tentang Perkoperasian. Bandung: Dinas Koperasi.

Indriantoro Dan Bambang Supomo. 2002. Metodologi Penelitian Bisnis (UntukAkuntansi Dan Manajemen,Edisi Pertama. Yogyakarta: BPFE 
Sugiyono, 2009, Metode Penelitian Kuantitatif, Kualitatif Dan R\&D, Bandung : Alfabeta

Iyanto, Bambang. 2001.Dasar-Dasar Pembelanjaan Perusahaan. Edisi Keempat Cetakan Keenam. Yogyakarta: BPFE

Kieso, Donald E, Jerry J. Weygandt. Terry D. Warfield 2008. Akuntansi Intermediate. Jakarta:Erlangga

Munir Fuady, Pengantar Hukum Bisnis, Bandung : Citra Aditya Bakti, 2001, Hal. 82

Peraturan Menteri Negara Koperasi Dan Usaha Kecil Dan Menengah Republik Indonesia Nomor : 20/Per/M.Kukm/Xi/2008 Tentang Pedoman Penilaian Kesehatan Koperasi Simpan Pinjam Dan Unit Simpan Pinjam Koperasi

Peraturan Menteri Negara Koperasi Dan Usaha Kecil Dan Menengahrepublik Indonesianomor : 14/Per/M.Kukm/XII/2009 tentang perubahan Atas Peraturan Menteri Negara Koperasi Dan Usahakecil Dan Menengah Nomor.20/Per/M.Kukm/XI/2008 Tentang pedoman Penilaian Kesehatan Koperasi Simpan Pinjam Dan Unit simpan Pinjam Koperasi

Peraturan Pemerintah Republik Indonesia Nomor 9 Tahun 1995 Tentang Pelaksanaan Kegiatan Usaha Simpan Pinjam Oleh Koperasi

Rudianto. 2010. Akuntansi Koperasi (Edisi Kedua). Jakarta: Erlangga

Simamora, Henry.2000. Akuntansi Basis Pengambilan Keputusan, Salemba Empat, Jakarta

Soedarsa, H. G., \& Natalia, D. (2016). Analisis Tingkat Kesehatan Koperasi Pada Koperasi Simpan Pinjam Di Kabupaten Tulang Bawang Barat. Jurnal Akuntansi Dan Keuangan, 7(2).

Soemarso, S. R. 2002 Akuntansi Suatu Pengantar. Jakarta Salemba Empat

Stice, Earl K, James D. Stice Dan K. Fred Skousen. 2009. Intermediete Accounting. Jakarta: Salemba Empat

Suarjaya, I. N., Cipta, W., \& Zukhri, A. (2015). Analisis Penyelesaian Kredit Macet Pada Koperasi Pasar Srinadi Klungkung. Jurnal Pendidikan Ekonomi Undiksha, 5(1).

Sucipto, A. (2015). Prediksi Kredit Macet Melalui Perilaku Nasabah Pada Koperasi Simpan Pinjam Dengan Menggunakan Metode Algoritma Klasifikasi C4. 5. Jurnal DISPROTEK, 6(1).

Sumarsono, Sony. 2003. Manajemen Koperasi: Teori Dan Praktek. Yogyakarta; Graha Ilmu

Surat Edaran Bank Indonesia Nomor 26/4/BPPP Tanggal 29 Mei 1993 Mengatur Masalah Penanganan Secara Maksimal Terhadap Kredit Bermasalah

Susilawati, R. A. E., \& Purwanto, N. (2016). Analisis Rescheduling\&Reconditioning Piutang Mitra Binaan Untuk Meningkatkan Kinerja Keuangan Pkbl Di Perum Jasa Tirta I. Jurnal Riset MahasiswaAkuntansi, 4(1).

Tri Wahyuni, D. (2011). Standar Penanganan Pinjaman Bermasalah Pada Koperasi Simpan Pinjam Sarana Aneka Jasa (Doctoral dissertation, Universitas Sebelas Maret).

Undang-Undang Republik Indonesia Nomor 12 Tahun 1967. Tentang PokokPokok Perkoperasi 
Warren S.Carl, James M Reeve, Jonathan E. Duchac. 2009. Pengantar

Akuntansi, Buku Satu, Alih Bahasa: Tim Salemba Empat. Jakarta:

Salemba Empat. 